\title{
Atypical Interfollicular Hyperplasia of Tonsils Resembling Mucosa-Associated Lymphoid Tissue Lymphoma: A Clinicopathological, Immunohistochemical Study and Epstein-Barr Virus Findings in 12 Cases
}

\author{
Yuko Kaneko,* Masaru Kojima,* Seiichiro Suzuki, Atsuko Takada, Hidetsugu Yamagishi, \\ Yoshimasa Nakazato, and Nobuhide Masawa
}

This study attempted to clarify the clinicopathological and immunohistochemical findings and presence or absence of Epstein-Barr virus (EBV) in tonsillar atypical interfollicular hyperplasia (AIFH). A total of 597 consecutive specimens from tonsillectomies performed in Dokkyo University School of Medicine between 1999 and July 2013 were reexamined. Using formalin-fixed, paraffin-embedded sections, histological and immunohistochemical analyses, and in situ hybridization (ISH) were performed. AIFH was identified in the tonsils in $12(2.0 \%)$ cases. These included 7 males and 5 females, aged 3 to 19 years (mean, 7). Histologically, there was expansion of the interfollicular areas by polymorphous infiltration resulting in distortion, but not obliteration of the normal tonsillar architecture. In some areas, the lymphoid follicles had hyperplastic germinal centers with ill-defined borders surrounded by sheet-like proliferation of polymorphous infiltrate showing a marginal zone distribution pattern. The infiltrate was composed of small to medium-sized (transformed) lymphocytes and immunoblasts accompanied by numerous plasma cells and plasmacytoid cells, and resembling monocytoid B cells. The numerous immunoblasts were MUM1 ${ }^{+}, \mathrm{CD} 10^{-}$, BCL-6- An ISH study demonstrated EBV-encoded small RNA-1 (EBER-1) ${ }^{+}$cells in 9 lesions. Moreover, in 3 lesions, numerous EBER- $1^{+}$cells were present in germinal centers as well as in interfollicular areas. The present study indicated that EBV may cause at least a portion of tonsillar AIFH in children and adolescents. In conclusion, an atypical lymphoid infiltration resulting in distortion of tonsillar architecture with numerous MUM1 ${ }^{+}, \mathrm{CD} 10^{-}$, BCL- $6^{-}$immunoblasts should raise the suspicion of a reactive process. $〔 J$ Clin Exp Hematop 54(2) : 111-116, 2014〕

Keywords: atypical interfollicular hyperplasia, tonsil, Epstein-Barr virus, immunohistochemistry, in situ hybridization

\section{INTRODUCTION}

Infectious mononucleosis (IM) is an acute lymphoproliferative disorder (LPD) that typically occurs in young patients and is usually caused by Epstein-Barr virus (EBV). ${ }^{1}$ The diagnosis of IM is usually based on clinical and serologic findings. ${ }^{1}$ However, lymphoid tissue biopsy may be performed when malignant lymphoma is a clinical consideration in patients demonstrating atypical clinical features. ${ }^{2-6}$

\footnotetext{
Received: February 18, 2014

Revised : April 1, 2014

Accepted: April 9, 2014

Department of Anatomic and Diagnostic Pathology, Dokkyo University School of Medicine, Mibu, Japan

*These authors contributed equally to this work.

Corresponding author: Masaru Kojima, M.D., Anatomic and Diagnostic Pathology, Dokkyo University School of Medicine, 880 Kita-Kobayashi, Mibu, Shimotsuga-gun, Tochigi 321-0293, Japan

E-mail: k-masaru@dokkyomed.ac.jp
}

Atypical features include an age over 30 years, generalized lymphadenopathy, or isolated lymphadenopathy at an unusual site, tonsillar mass, negative heterophil antibody titer, or the absence of atypical lymphocytosis in peripheral blood..$^{2-6}$ In the tonsils, one of the authors has reported EBV-associated reactive LPDs resembling mucosa-associated lymphoid tissue (MALT)-type lymphoma. ${ }^{5}$ In 2012, Louissaint et al. examined 15 cases of tonsillar biopsy specimens of IM, and reported that all cases featured architectural distortion by polymorphous infiltration in the interfollicular area. ${ }^{6}$ In 2004, Attygalle et al. reported atypical marginal zone hyperplasia of the tonsils. ${ }^{7}$ However, EBV findings were not analyzed in their report. Moreover, little is known about the clinicopathological and immunohistochemical findings regarding atypical interfollicular hyperplasia (AIFH) in the tonsils. To shed light on AIFH in the tonsils, we conducted clinicopathological, immunohistochemical, and in situ hybridization (ISH) analyses in 12 such cases in the Northern Kanto region of 
Japan.

\section{MATERIALS AND METHODS}

This study was based on 597 consecutive specimens from tonsillectomies performed in Dokkyo University School of Medicine between 1999 and July 2013. Clinical findings were obtained from hospital records.

Three-micrometer-thick sections were cut from formalinfixed, paraffin-embedded tissues, and stained with hematoxylin-eosin and Giemsa. Immunohistochemistry was performed on paraffin sections using a Histofine Histostainer (Nichirei Bioscience Inc., Tokyo, Japan) according to the manufacturer's instructions or the avidin-biotin peroxidase complex method. A panel of antibodies against human PS-1 (CD3; Nichirei Bioscience Inc.), 56C6 (CD10; Nichirei Bioscience Inc.), L26 (CD20; Nichirei Bioscience Inc.), 2G9 (CD21; Leica Biosystems, Newcastle, UK), SP23 (CD23; Nichirei Bioscience Inc.), 137B4 (CD27; Leica Biosystems), 1 G12 (CD30; Nichirei Bioscience Inc.), MT-1 (CD43; Leica Biosystems), LN22 (bcl-6; Leica Biosystems), interferon regulatory factor 4 (MUM-1; Dako A/S, Glostrup, Denmark), CS1-4 (latent membrane protein-1 [LMP-1]; Dako A/S), PE2 (Epstein-Barr virus nuclear antigen-2 [EBNA-2]; Dako A/S), and AE1/3 (cytokeratin; Nichirei Bioscience Inc.) was used.

ISH with EBV-encoded small RNA-1 (EBER-1) oligonucleotides, and $x$ - and $\lambda$-light chains was performed in formalin-fixed, paraffin-embedded sections using a hybridization kit (Dako Y5200, Y5201, and K5202).

\section{RESULTS}

\section{Incidence of $\mathrm{AIFH}$}

AIFH was identified in the tonsils in 12 (2.0\%) of the 597 cases (Table 1).

\section{Clinical findings}

The patients, 7 males and 5 females, ranged in age from 3 to 19 years, with a mean age of 7 and a median age of 5 (Table 1). Nine cases (No. 1, 3-10) were diagnosed with sleep apnea syndrome, 2 (No. 11, 12) with habitual angina, and 1 (No. 2) with chronic otitis media. Ten patients (No. 1, $3-6,8-12)$, presented with a bilateral tonsillar mass, whereas only 2 cases (No. 2, 7) presented with a right tonsillar mass. Three cases (No. 3, 4, 6) had a history of bronchial asthma, 2 (No. 7, 8) had allergic rhinitis, and 1 (No. 12) had atopic dermatitis. One case (No. 12) had a history of IM 2 months before tonsillectomy. Follow-up information was available for all 12 patients for periods ranging from 1 to 36 months, with a mean of 19 and a median of 6 months.

\section{Histological, immunohistochemical, and EBV findings}

In a low-power field, in all cases, there was expansion of the interfollicular areas by polymorphous infiltration resulting in distortion, but not obliteration of the normal tonsillar architecture (Fig. 1a). In some areas, the lymphoid follicles had hyperplastic germinal centers with ill-defined borders, surrounded by the sheet-like proliferation of polymorphous infiltration showing a marginal zone distribution pattern (Fig. 1a). In a high-power field, the interfollicular area was diffusely infiltrated by a polymorphous infiltrate of small to mediumsized (transformed) lymphocytes and immunoblasts accompanied by numerous plasma cells and plasmacytoid cells, and admixed with histiocytes and high endothelial venules (Fig. 1b). Immunoblasts were frequently present in aggregates and showed mitotic activity (Fig. 1c). Some of the immunoblasts resembled mononuclear Hodgkin cells; however, there were no multinucleated Reed-Sternberg-like cells in any of the lesions (Fig. 1c). In all cases, some of the medium-sized lymphocytes had irregular or bean-shaped nuclei with 1-3 inconspicuous nucleoli, and showed abundant pale cytoplasm

Table 1. Summary of 12 cases

\begin{tabular}{|c|c|c|c|c|c|c|c|c|}
\hline Case No & Age & Gender & Site & Symptom & Clinical diagnosis & Allergy & Follow up (mon) & EBER \\
\hline 1 & 3 & M & Bil. tonsil & Snooring, mass & Sleep apnea syndrome & $(-)$ & 3 & A few \\
\hline 2 & 4 & $\mathrm{~F}$ & Rt. tonsil & Mass & Chronic otitis media & $(-)$ & 23 & A few \\
\hline 3 & 4 & M & Bil. tonsil & Snooring, mass & Sleep apnea syndrome & Bronchial asthma & 25 & A few \\
\hline 4 & 4 & M & Bil. tonsil & Snooring, mass & Sleep apnea syndrome & Bronchial asthma & 12 & A few \\
\hline 5 & 4 & M & Bil. tonsil & Snooring, mass & Sleep apnea syndrome & $(-)$ & 6 & $(-)$ \\
\hline 6 & 4 & M & Bil. tonsil & Snooring, mass & Sleep apnea syndrome & Bronchial asthma & 36 & $(-)$ \\
\hline 7 & 5 & M & Rt. tonsil & Snooring, mass & Sleep apnea syndrome & Allergic rhinitis & 1 & A few \\
\hline 8 & 5 & M & Bil. tonsil & Snooring, mass & Sleep apnea syndrome & Allergic rhinitis & 6 & A few \\
\hline 9 & 6 & $\mathrm{~F}$ & Bil. tonsil & Snooring, mass & Sleep apnea syndrome & $(-)$ & 6 & Numerous \\
\hline 10 & 6 & $\mathrm{~F}$ & Bil. tonsil & Nasal obstruction, mass & Sleep apnea syndrome & $(-)$ & 3 & $(-)$ \\
\hline 11 & 17 & $\mathrm{~F}$ & Bil. tonsil & Fever, sore throat, mass & Habitual angina & $(-)$ & 2 & Numerous \\
\hline 12 & 19 & $\mathrm{~F}$ & Bil. tonsil & Fever, sore throat, mass & Habitual angina, History of IM & Atopic dermatitis & 5 & Numerous \\
\hline
\end{tabular}

Rt, right; Bil., bilateral; IM, infectious mononucleosis; m, months; EBER, Epstein-Barr virus-encoded small RNA; P, positive 
and visible cell borders (Fig. 1b). These cells somewhat resembled monocytoid $\mathrm{B}$ cells.

In a low-power field, staining with CD20 and CD3 demonstrated a focally expanding interfollicular area (Fig. 1d, 1e). Staining with CD20 and CD3 showed mixed small and medium-sized lymphocytes, and immunoblasts. However, the majority of the immunoblasts were CD20-positive (Fig. $1 \mathrm{f}, 1 \mathrm{~g})$. A portion of medium-sized to large B lymphocytes including immunoblasts were $\mathrm{CD} 10^{-}, \mathrm{CD} 21^{-}, \mathrm{CD} 23^{-}, \mathrm{CD} 27^{-}$,
$\mathrm{CD}_{4} 3^{+}$(Fig. 1h), and bcl-6 ${ }^{-}$. Moreover, numerous large lymphoid cells demonstrated strong MUM1-positivity (Fig. 2a). A portion of immunoblasts including Hodgkin cells were $\mathrm{CD} 30^{+}$(Fig. 2b). ISH study demonstrated the polytypic nature of the B lymphocytes (Fig. 2c, 2d). AE1/3 immunostaining showed the prominence of B cells within the tonsillar epithelium in all 12 cases. Staining with CD21 and CD23 highlighted the meshwork of follicular dendritic cells. Although the majority of the follicular dendritic cell mesh-
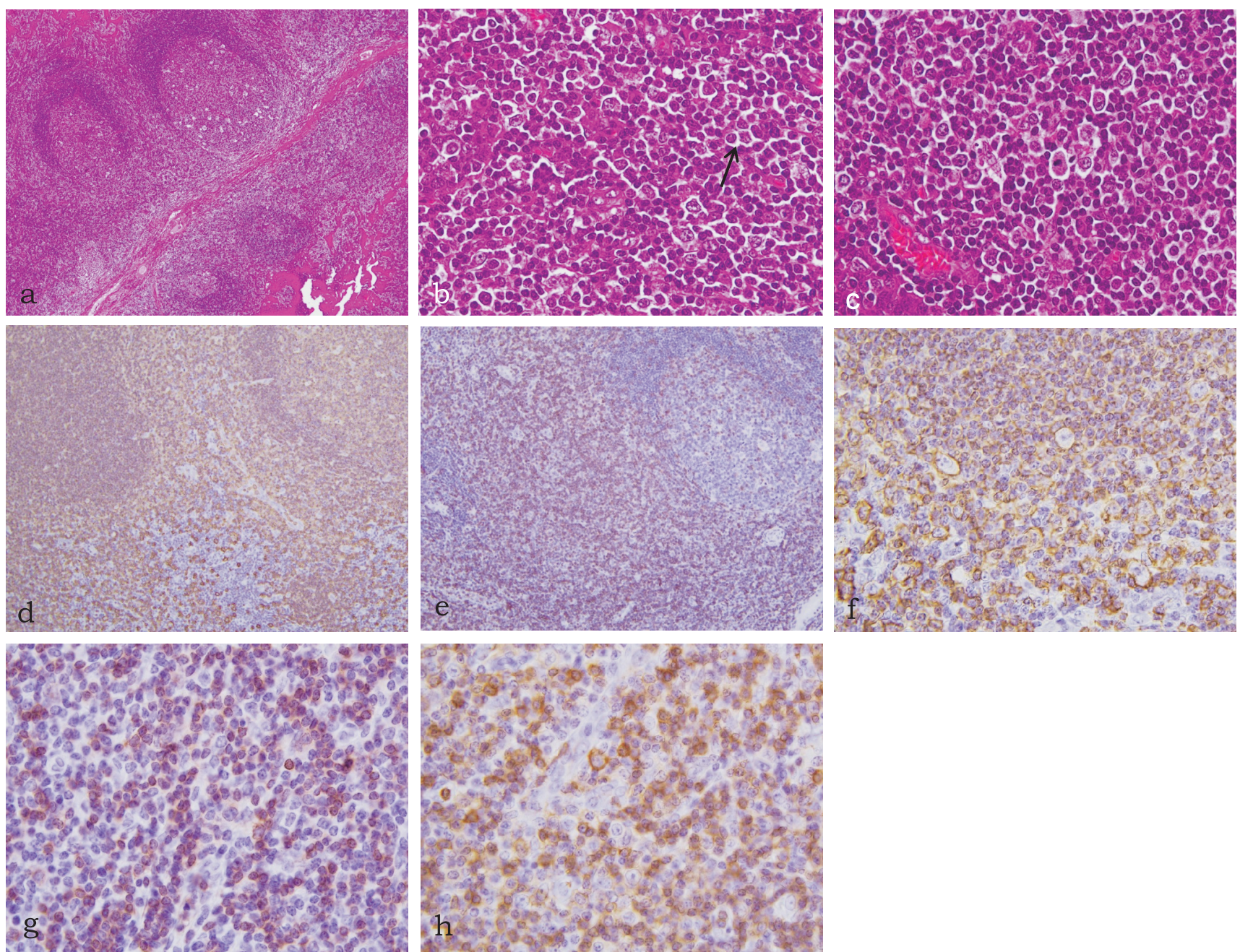

Fig. 1. Histological and immunohistochemical findings. (1a) At a low-power magnification, there was expansion of the interfollicular areas by polymorphous infiltration. The lymphoid follicles had hyperplastic germinal centers with ill-defined borders, surrounded by a marginal zone distribution pattern. Case 12, H\&E stain, $\times 10$. (1b) In a high-power field, the interfollicular area was diffusely infiltrated by a polymorphous infiltrate of small to medium-sized (transformed) lymphocytes, immunoblasts accompanied by numerous plasma and plasmacytoid cells, and admixed with histiocytes and high endothelial venules. Note a cell somewhat resembling monocytoid B cells (arrow). Case 12, H\&E stain, $\times 100$. (1c) Immunoblasts were present in aggregates and showed mitotic activity. Some of the immunoblasts resembled mononuclear Hodgkin cells. Case 12, H\&E stain, $\times 100$. (1d \& 1e) In a low-power field, CD20 (1d) and CD3 (1e) immunostaining demonstrated a focally expanding interfollicular area. Case $12, \times 25$. (1f \& $\mathbf{1 g})$ In a high-power field, CD20 (If) and CD3 ( $1 g)$ immunostaining demonstrated the mixed nature of small and medium-sized lymphocytes, and immunoblasts. However, the majority of the immunoblasts were CD20-positive. Case 12, $\times 100$. (1h) A portion of medium-sized to large B lymphocytes including immunoblasts were CD43-positive. Case $12, \times 100$. 
work maintained a regular arrangement, a portion of the meshwork was broken into clusters (Fig. 2e).

On ISH, a positive signal for EBERs was identified in 9 cases (No. 1-4, 7, 8, 9, 11, 12) (Table 1). More than 200 EBER- $1^{+}$cells were located in the germinal centers as well as interfollicular areas in 3 cases (No. 9, 11, 12) (Fig. 2f). Up to
10 EBER-1 $1^{+}$cells were located in the interfollicular area and/or germinal centers in 6 cases (No. 1-4, 7, 8).

Only a few LMP- $1^{+}$lymphoid cells were located in the interfollicular area in 2 cases (No. 11, 12). However, there were no EBNA-2 $2^{+}$cells in any of the 12 lesions.
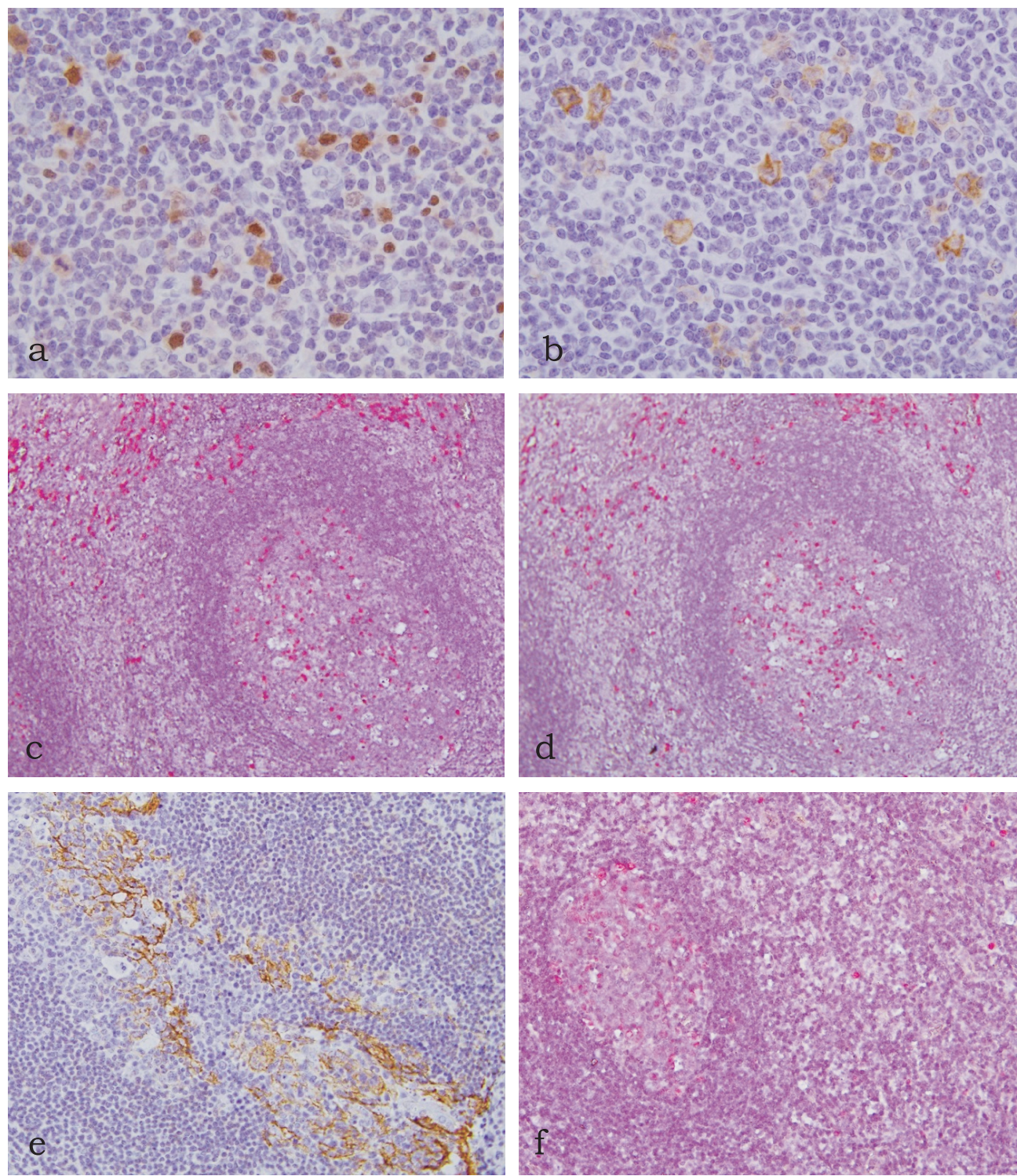

Fig. 2. Immunohistochemical and in situ hybridization findings. (2a) The majority of the large lymphoid cells showed MUM1-positivity. Case 12, $\times 100$. (2b) A portion of immunoblasts including those resembling Hodgkin cells were CD30-positive. Case $12, \times 100 .(2 c \& 2 d)$ The in situ hybridization study demonstrated the polytypic nature of B lymphocytes. $(2 c) \varkappa,(2 d) \lambda$. Case 12, $\times 100$. (2e) CD23 immunostaining demonstrated breakage of the meshwork of the follicular dendritic cell network. Case 12, $\times 25$. $(2 f)$ There were numerous $\mathrm{EBER}^{+}$cells in a germinal center as well as interfollicular areas. Case $12, \times 25$. 


\section{DISCUSSION}

AIFH of the tonsils was observed in only $2 \%$ of the resected tonsillar specimens in our series. However, in patients younger than 20 years old, AIFH occupied 4\% (12/310) of our series. All 12 cases in our study were children or young adolescents. Moreover, in all cases, atypical marginal zone hyperplasia appeared. As Attygalle et al. reported, ${ }^{7}$ tonsillar AIFH might be an LPD in children.

Although MALT-type lymphoma rarely affects children or young adults, notably, a number of cases have been reported involving the tonsil. ${ }^{7-9}$ As Attygalle et al. emphasized, ${ }^{7}$ differential diagnosis between AIFH and MALT lymphoma may occasionally be difficult with small biopsy specimens from the tonsils. In the present 12 cases, marginal zone distribution pattern of the lesion including large B cells and simulating monocytoid B cells may be misinterpreted as diffuse large B-cell lymphoma arising from a low-grade MALT-type lymphoma. ${ }^{10}$ Indeed, using resected tonsils, one of the authors reported that a portion of tonsillar diffuse large B-cell lymphoma may arise from a low-grade MALT-type lymphoma. ${ }^{10}$ Moreover, a portion of the medium-sized to large B cells demonstrated the "aberrant" expression of CD43. ${ }^{11,12}$ Breakage of the meshwork of the follicular dendritic cell network also suggested the follicular colonization of MALT-type lymphoma. ${ }^{11}$ When present in B-cell LPDs, CD43 expression is considered a fairly reliable marker of malignancy. ${ }^{11,12}$ Lai et al. reported that about $30 \%$ of MALTtype lymphomas express CD43. ${ }^{12}$ However, Attygalle et al. reported $\mathrm{CD}_{4} 3^{+}$reactive marginal zone hyperplasia in tonsils. ${ }^{7}$ Lee also reported that 17/20 (85\%) cases showed strong coexpression of CD43 by benign perifollicular B cells in the terminal ileum. ${ }^{13} \mathrm{CD} 43$ expression was also reported in reactive plasmacytosis. ${ }^{14} \mathrm{CD} 43$ expression of our series may be the aberrant expression of reactive B cells. However, to clarify this issue, further study is needed.

In EBV-unrelated LPDs, a few small EBER-1 $1^{+}$lymphocytes are occasionally seen in the interfollicular area. ${ }^{15,16}$ Kurth et al. concluded that the presence of numerous EBER$1^{+}$cells in the germinal centers as well as interfollicular area appears to be a characteristic finding of recent EBV infection (infectious mononucleosis pattern). ${ }^{17}$ EBER-1 ${ }^{+}$cells were identified in 9 cases. More than 200 EBER- $1^{+}$cells were located in the germinal centers as well as interfollicular area in 3 cases. However, only 1 of the 3 cases had a history of IM.

In the tonsils, reactivity of lymphoid cells for EBV has been reported in lymphoid tissues from a high percentage of patients with previously asymptomatic EBV infection. ${ }^{18,19}$ Only a few small $\mathrm{EBV}^{+}$lymphocytes were usually detected in patients with previously asymptomatic infection, ${ }^{18-20}$ whereas numerous large EBER-1 $1^{+} \mathrm{B}$ cells were observed in 3 lesions. These 3 cases were considered to be primary EBV infection or reactivation. ${ }^{17}$

In children, Endo et al. reported that EBER-1 $1^{+}$lymphocytes were detected in approximately $30 \%$ of tonsillar hypertrophy and recurrent tonsillitis. ${ }^{21}$ Dias et al. also found a few LMP- $1^{+}$lymphocytes in $37.5 \%$ of recurrent tonsillitis. ${ }^{22}$ They concluded that the tonsils of children can be colonized by EBV, and that the virus may be involved in tonsillar hypertrophy and recurrent tonsillitis. ${ }^{21,22}$

When IM is not suspected clinically, microscopic findings in the tonsillar specimens can pose serious differential diagnostic problems for surgical pathologists, and may lead to a misdiagnosis of malignant lymphoma. As Louissant et al. ${ }^{6}$ suggested, an atypical lymphoid infiltrate with numerous $\mathrm{MUM1}^{+}$, CD10-, BCL- $6^{-}$immunoblasts should raise the suspicion of a reactive process, such as IM, and warrants additional consideration before a diagnosis of lymphoma is made.

The present study indicated that EBV may cause at least a portion of tonsillar AIFH in children and adolescents.

CONFLICT OF INTEREST : The authors declare no conflicts of interest.

\section{REFERENCES}

1 Henle W, Henle GE, Horwitz CA: Epstein-Barr virus specific diagnostic tests in infectious mononucleosis. Hum Pathol 5:551565, 1974

2 Childs CC, Parham DM, Berard CW: Infectious mononucleosis. The spectrum of morphologic changes simulating lymphoma in lymph node and tonsils. Am J Surg Pathol11:122-132, 1987

3 Strickler JG, Fedeli F, Horwitz CA, Copenhaver CM, Frizzera G: Infectious mononucleosis in lymphoid tissue. Histopathology, in situ hybridization, and differential diagnosis. Arch Pathol Lab Med 117:269-278, 1993

4 Mills SE, Gaffey MJ, Frierson HF: Tumor of the Upper Aerodigestive Tract and Ear. In: Atlas of Tumor Pathology. 3rd series, Fascicle 26, Bethesda MD, Armed Forces Institute of Pathology, pp.204-206, 2000

5 Kojima M, Nakamura N, Itoh H, Shimizu K, Shimizu K, et al.: Epstein-Barr virus-related atypical lymphoproliferative disorders in Waldeyer's ring: A clinicopathological study of 9 cases. Pathobiology 77:218-224, 2010

6 Louissaint Jr A, Ferry JA, Soupir CP, Hasserjian RP, Harris NL, et al:: Infectious mononucleosis mimicking lymphoma: distinguishing morphological and immunophenotypic features. Mod Pathol 25:1149-1159, 2012.

7 Attygalle AD, Liu H, Shirali S, Diss TC, Loddenkemper C, et al.: Atypical marginal zone hyperplasia of mucosa-associated lymphoid tissue: a reactive condition of childhood showing immunoglobulin lambda light-chain restriction. Blood 104:3343-3348, 2004

8 Menárguez J, Mollejo M, Carrión R, Oliva H, Bellas C, et al.: Waldeyer ring lymphomas. A clinicopathological study of 79 
cases. Histopathology 24:13-22, 1994

9 Taddesse-Heath L, Pittaluga S, Lynn S, Busse M, Raffeld M, et al.: Marginal zone B-cell lymphoma in children and young adults. Am J Surg Pathol 27:522-531, 2003

10 Kojima M, Nakamura N, Shimizu K, Tamaki Y, Itoh $\mathrm{H}$, et al:: Marginal zone B-cell lymphoma among primary B-cell lymphoma of Waldeyer's ring: Histopathologic and immunohistochemical study of 16 tonsillectomy specimens. Int J Surg Pathol 16:164170,2008

11 Isaacson PG, Chot A, Nakamura S, Müller-Hermelink HK, Harris $\mathrm{NL}$, et al.: Extranodal marginal zone B-cell lymphoma of mucosa associated lymphoid tissue (MALT lymphoma). In: Swerdlow SH, Campo E, Harris NL, Jaffe ES, Pileri SA, et al. (eds): World Health Organization Classification of Tumours, WHO Classification of Tumours of Haematopoietic and Lymphoid Tissues. 4th ed, Lyon, International Agency for Research on Cancer (IARC), pp.214-217, 2008

12 Lai R, Weiss LM, Chang KL, Arber DA: Frequency of CD43 expression in non-Hodgkin lymphoma. A survey of 742 cases and further characterization of rare $\mathrm{CD}_{4} 3^{+}$follicular lymphomas. Am J Clin Pathol 111:488-494, 1999

13 Lee PS, Beneck D, Weisberger J, Gorczyca W: Coexpression of CD43 by benign $\mathrm{B}$ cells in the terminal ileum. App1 Immunohistochem Mol Morphol 13:138-141, 2005

14 Beschorner R, Horny H-P, Petruch UR, Kaiserling E: Frequent expression of heamopoietic and non-heamatopoietic antigens by reactive plasma cells: an immunohistochemical study using formalin-fixed, paraffin-embedded tissue. Histol Histopathol 14:
805-812, 1999

15 Niedobitek G, Herbst H, Young LS, Brooks L, Masucci MG, et al:: Patterns of Epstein-Barr virus infection in non-neoplastic lymphoid tissue. Blood 79:2520-2526, 1992

16 Deamant FD, Albújar PF, Chen YY, Weiss LM: Epstein-Barr virus distribution in nonneoplastic lymph nodes. Mod Pathol 6: 729-732, 1993

17 Kurth J, Hansmann ML, Rajewsky K, Küppers R: Epstein-Barr virus-infected $\mathrm{B}$ cells expanding in germinal centers of infectious mononucleosis patients do not participate in the germinal center reaction. Proc Natl Acad Sci U S A 100:4730-4735, 2003

18 Tao Q, Srivastava G, Chan AC, Chung LP, Loke SL, et al.: Evidence for lytic infection by Epstein-Barr virus in mucosal lymphocytes instead of nasopharyngeal epithelial cells in normal individuals. J Med Virol 45:71-77, 1995

19 Tao Q, Srivastava G, Chan AC, Ho FC: Epstein-Barr-virus infected nasopharyngeal intraepithelial lymphocytes. Lancet 345: 1309-1310, 1995

20 Hudnall SD, Ge Y, Wei L, Yang NP, Wang HQ, et al.: Distribution and phenotype of Epstein-Barr virus-infected cells in human pharyngeal tonsils. Mod Pathol 18:519-527, 2005

21 Endo LH, Ferreira D, Montenegro MC, Pinto GA, Altemani A, et al:: Detection of Epstein-Barr virus in tonsillar tissue of children and the relationship with recurrent tonsillitis. Int $\mathrm{J}$ Pediatr Otorhinolaryngol 58:9-15, 2001

22 Dias EP, Rocha ML, Carvalho MO, Amorim LM: Detection of Epstein-Barr virus in recurrent tonsillitis. Braz J Otorhinolaryngol 75:30-34, 2009 